\title{
Artificial Intelligence in Bio-Medical Domain
}

\author{
An Overview of AI Based Innovations in Medical
}

\author{
Muhammad Salman, Abdul Wahab Ahmed, Omair Ahmad Khan, Basit Raza, Khalid Latif \\ Department of Computer Science \\ COMSATS Institute of Information Technology \\ Islamabad 45550, Pakistan
}

\begin{abstract}
In this era and in the future, artificially intelligent machines are replacing and playing a key role to enhance human capabilities in many areas. It is also making life style better by providing convenience to all including normal human beings and professionals as well. That is why AI is gaining huge attention and popularity in the field of computer science by which it has revolutionized the rapidly growing technology known as expert system. The applications of AI are working in many areas with huge impact and being used widely as well. AI provides quality and efficiency in almost every area, we are evolving it in. The main purpose of this paper is to explore the area of medical and health-care with respect to AI along with 'Machine Learning', and 'Neural Networks'. This work explores the current use of AI in innovations, in the particular field of Bio-Medical and evaluated that how it has improved hospital inpatient care and other sectors related to it i.e. smart medical home, virtual presence of doctors and patients, automation in diagnostic, etc. that has changed the infrastructure of medical domain. Finally, an investigation of some expert systems and applications is made. These systems and applications are widely used throughout the world and a ranking mechanism of their performance has proposed accordingly in an organized manner. We hope, this work will be helpful for the researchers coming to this particular area and to provide a syntactic information that how computer science (i.e. AI, ANN, ML) is revolutionizing the field of biomedical and healthcare.
\end{abstract}

Keywords-Artificial intelligence; expert systems; bio-medical; healthcare; innovations

\section{INTRODUCTION}

Artificial intelligence (AI) [1] came into being as an inspiration whose ultimate goal was to copy and learn like human brain and to determine the upcoming considerations and real world challenges with a perfect intelligent approach. Scientists and researchers everywhere in the globe were terribly excited regarding advancements in innovations those have arisen from a natural need to form newer and higher technologies. These innovations may facilitate the humanity to increase on the far side of their own physical caliber. The promise of AI thought has continuously been on the horizon from realistic science to the imagination in movies and literature. AI for the most part permits the capability to store and process vast amounts of information in an intelligent manner, and specifically translating that data into information that could be used practical tools. Since its origination, AI has been deployed for extremely selective defense and area exploration applications whereby its success in resolving issues for specific areas similar to risk prediction is concerned. Now, gradual transition of its utility in health care is being widely intimated through AI-based systems those can afford higher diagnosing, cure and treatment of exhausting conditions.

Artificial intelligence has attracted many users over the past, it supports medical sciences, businesses, scientific researches etc. These systems when implemented with great cautions, gave surprisingly accurate results and avoided errors likely happened by humans [2]. These systems never falter because they follow a specific track to achieve a goal by using the information provided [3], [4]. In case if we don't have enough knowledge for designing some system, system is provided with past knowledge base to develop itself and make decisions on that knowledge base.

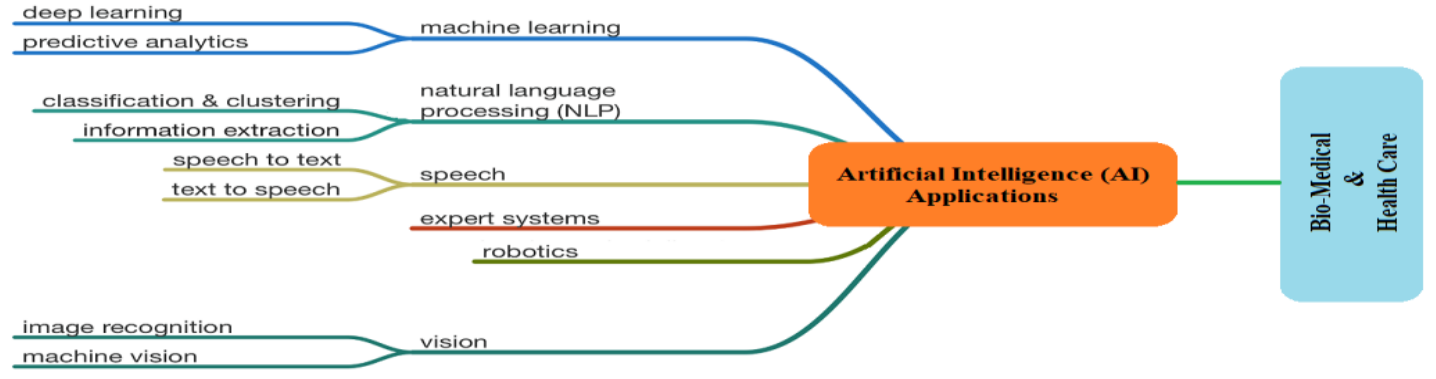

Fig. 1. Branches of AI applied in biomedical domain.

$\mathrm{AI}$ in health care and drugs may be a new analysis space that mixes refined realistic and computational approaches with the insights of professional doctors to provide new innovations for rising health care in the form of tools. AI is the study of concepts, that modifies computers to try and to do the items that create individuals intelligent. The ultimate task or goal of 
$\mathrm{AI}$ is to form or to evolve computers more and more helpful and to grasp the principles that make intelligence attainable. The branches of AI working in the domain of healthcare and biomedical are shown in Fig. 1.

Medicine could be an area which acquires technology to much more extent. With the boost of our desires and expectations of the very best quality medical diagnosis in health care and the ascension of additional elaborated medical information leave the doctors to pay proper attention and to give proper time to each case. It is also quite tough for a physician to stay up to date with the most recent developments in his field. As a result, due to lack of attention and adequate time, many of the medical recommendations are based on speedy diagnosis of the case, hoping with the physician's unaided experience. Solely, in the very rare cases, there may have a situation to utilize the recent research and methodologies to ensure confidence for both side i.e. doctor and patient and to ensure that, most recent information is delivered to secure any specific patient but not applicable in general.

It is known that, computers are quite intellectual as well as have the capacity to deliver as instrument used for detection, and these aspects could be integrated to improve and to investigate the medical diagnosis and aid tool. Demonstrator to AI research is that physicians and therefore the computer can interact in disrupted communication and dialogue, system ceaselessly being attentive of all the knowledge we are having in laboratory, diagnosis reports, finding history, physical findings, and also informing doctor with foremost appropriate report of diagnosis and by suggesting the suitable and fruitful prescription course for the patient.

Rest of the paper follows as Section I(A) explains the different aspects of medical domain where AI is working whereas Section I(B) explores a few pioneer expert laboratories. Section II shows the glimpses of smart home mechanism with different aspects being evolved in smart healthcare home. Section III demonstrates recognized expert systems and applications which are being used worldwide with exception and follows Section IV that contain the concise information and grading of expert system as an information in tabular form where on the basis of performance some analysis is made by proposing grades. At the end, Section V elaborates importance and future directions of $\mathrm{AI}$ in the particular domain of bio-medical.

\section{A. Effectiveness of AI in Medical}

Artificial intelligence is what provides computers the power to observe, learn, think, reason, and even perceive human emotions, permitting computers to do quite simply repetitive tasks. Within the medical field, AI is being designed to help doctors (not replace them) within the effort to cut back the death rate among patients awaiting care from specialists. There is a huge range of aspects in Bio-Medical domain where AI in conjunction with Machine Learning (ML) and natural language processing (NLP) has effects on it. During this section we are going to discuss about the ways that are primarily associated with robotics and machine learning. Table 1 shows the different aspects of AI which are improving the medical field to much extent and providing quick and accurate health facilities by reducing the costs in extra.

\section{B. Expert Laboratories and Clinical Information Systems}

Now computer scientists are working on innovative applications which will improve diagnostic techniques and will help to classify diseases without human error. Resources will be managed in a better way by using AI. These systems will also help to avoid procedures which are hazardous to health like X-rays and other electromagnetic waves [5]. The focus of next development of Aml systems should be such, that they are less harmful to humans. All we need is a joint venture of experts from different fields. There are some expert systems those were the very first expert systems for diagnostic purpose.

a) Puff is an expert system which is used for automatic clarification of pulmonary function. Most likely Puff was the first AI expert system which has been used in biomedical field in San Francisco by 1977. PUFF can use to test the patient who is suffering from lungs disease also then pulmonary physiologist depicts its presence and generates recommendations and reports for the patient's file.

b) Germ Watcher is an expert system that observes microbiological information from different hospitals and laboratory systems. It classifies those microbiology cultures that produce hospital's collected viral and warn the recommended department of U.S. for disease control.

c) $\underline{\boldsymbol{P E I R S}}$ (Pathology Expert Interpretative Reporting System) appends interpretative comments to pathology reports. During its working, the system generated nearly 80100 patients reports on daily basis, having $95 \%$ accuracy in the diagnosis. The major areas of system's reports include thyroid function tests, arterial blood gases, urine and plasma, human chorionic gonadotrophin and alpha fetoprotein, and glucose tolerance tests, etc.

The web references of these expert systems are mentioned below ${ }^{1},{ }^{2},{ }^{3}$ :

\footnotetext{
${ }^{1}$ http://www.openclinical.org/aisp_puff.html

${ }^{2}$ http://www.openclinical.org/aisp_germwatcher.html

${ }^{3}$ http://www.openclinical.org/aisp_peirs.html
} 
TABLE I. EFFECTIVENESS OF AI IN MEDICAL

\begin{tabular}{|c|c|c|}
\hline Aspect & Description & Acknowledgment \\
\hline Robotics & $\begin{array}{l}\text { Robotic is based on: } \\
\text { - Hollywood amusement } \\
\text { - } \quad \text { chi-Fi novels } \\
\text { - } \quad \text { Still AI is nood as evolved as the actor Spielbergian } \\
\text { expectations of evolutions }\end{array}$ & $\begin{array}{l}\text { - AI has arisen in medication } \\
\text { It is to remodel all the fields like education, } \\
\text { medical, economics, etc. }\end{array}$ \\
\hline $\begin{array}{l}\text { Fast and Precise } \\
\text { Diagnostics }\end{array}$ & $\begin{array}{l}\text { Through the AI: } \\
\text { - Human brain is imitated with Artificial Neural Network. } \\
\text { - These Neural Networks has power to learn. } \\
\text { - These are very promising in the diagnosis } \\
\text { - } \quad \text { Accurate and Quick methods }\end{array}$ & $\begin{array}{l}\text { Disease Diagnosed: } \\
\text { - Melanoma } \\
\text { - } \quad \text { Optical Issues } \\
\text { Huge advancements to cure the different types of } \\
\text { cancer }\end{array}$ \\
\hline Therapeutic Robots & $\begin{array}{l}\text { - Alzheimer's patients get assistance through therapeutic } \\
\text { robots. } \\
\text { - It came into view to deal with human health impact } \\
\text { produced from caressing the animals. }\end{array}$ & $\begin{array}{l}\text { Robotic pets facilitate: } \\
\text { - } \quad \text { Nurture Human Brain Operate } \\
\text { Delays cognitive aspect which is responsible to } \\
\text { improve quality of life. } \\
\text { Decreases the reliance on social services, which } \\
\text { helps a human to stay in home with less medical } \\
\text { help. }\end{array}$ \\
\hline $\begin{array}{l}\text { Reduces Errors } \\
\text { associated with Human } \\
\text { Fatigue }\end{array}$ & $\begin{array}{l}\text { Human Doctors Errors: } \\
\text { - Diagnose almost } 80 \text { patients a week } \\
\text { - } \quad \text { Exhausting to pay attention to the needs of each and } \\
\text { every patient. } \\
\text { Whereas, AI based systems are not limited in the work } \\
\text { hours and human fatigues. }\end{array}$ & $\begin{array}{l}\text { - Like Spell Checker } \\
\text { - Helping Physicians to reduce the human like } \\
\text { mistakes } \\
\text { - Providing Relief to overwhelm with different } \\
\text { tasks. }\end{array}$ \\
\hline $\begin{array}{l}\text { Decrease in Medical } \\
\text { Cost }\end{array}$ & $\begin{array}{l}\text { How cost can be reduced: } \\
\text { - } \quad \text { Reducing the work place visits to almost zero. } \\
\text { - Online Care is provided. } \\
\text { Patient just update his/her medical reports while staying } \\
\text { in } \\
\text { home and saves the time, energy and cost to travel for a } \\
\text { work place }\end{array}$ & $\begin{array}{l}\text { - Huge amount of money is getting saved by } \\
\text { different technologies evolutions like drug's } \\
\text { interactions, precise diagnosis } \\
\text { - } \quad \text { Reduced error is also a way to save money }\end{array}$ \\
\hline Movement Assistance & $\begin{array}{l}\text { - Medical personnel are not enough to provide assistance } \\
\text { and the field is struggling in it. } \\
\text { - So, robots seem to be very prominent to utilize as } \\
\text { manpower to assist the patients in movements. } \\
\text { - These are good for repetitive tasks like medical } \\
\text { pharmacy and physical therapy. }\end{array}$ & $\begin{array}{l}\text { - HAL } 5 \text { (Hybrid Helpful Limb) suit has overcome } \\
\text { the mobility issues. } \\
\text { - One can carry the double weight through this } \\
\text { A well promising tool for health care } \\
\text { professionals. }\end{array}$ \\
\hline Improved Radiology & $\begin{array}{l}\text { Radio surgery: } \\
\text { - Cyber-Knife, provides the facility to eliminate tumor at } \\
\text { any place in the body. } \\
\text { Image oriented and guided technologies are use with the } \\
\text { computational system to facilitate the patient's } \\
\text { movements throughout the process }\end{array}$ & $\begin{array}{l}\text { Without harming other healthy tissue, it targets } \\
\text { accurately to the tumor and eliminate it by } \\
\text { imposing radiation on it }\end{array}$ \\
\hline Virtual Presence & $\begin{array}{l}\text { - You are not supposed to leave your bed once more for } \\
\text { any process. } \\
\text { Doctors are able to see the matters and to communicate } \\
\text { with patients and workers while not being present there. } \\
\text { - So, they are not bound to one workplace and can deal the } \\
\text { matters from far place as being at front. }\end{array}$ & $\begin{array}{l}\text { - It is the most helpful because if one is not in a } \\
\text { condition to travel then still can get diagnosis while } \\
\text { staying in home } \\
\text { - Doctor can also avail the facility to deal patients at } \\
\text { different locations }\end{array}$ \\
\hline $\begin{array}{l}\text { Invasive Surgery } \\
\text { Advances }\end{array}$ & $\begin{array}{l}\text { - The system which has evolved fantastic achievements in } \\
\text { surgery in known as Da Vinci Si HD Surgical System. } \\
\text { Da Vinci Si HD provides with clear, accurate and } \\
\text { superior visuals in imaging. }\end{array}$ & $\begin{array}{ll}\text { It Delivers: } \\
\text { - } & \text { Smaller Incisions } \\
\text { - } & \text { Cut Back Patient Pain } \\
\text { - } & \text { Reduces medication } \\
\text { - } & \text { shorten hospital stays } \\
\end{array}$ \\
\hline
\end{tabular}




\section{SMART Home/HeAlthCARE FACILITATING TOOLS}

In this section, we provide some of directly data taking techniques that, if connected with AI technologies can help out to achieve much more advancements in the field of medical and can provide fast and quick health care services in home office and anywhere i.e. smart-home, smart-hospital, etc.

1) Activity Recognition: As human activities contain huge amount of data which can be predicted through psychological and through knowledge based systems. As AI systems are always there, examining the desires and the requirements of the human beings for which these are implemented. Therefore, it requires data about the activities of which it is examining or focusing [6]. And there are huge number of techniques in [7], [8] for the purpose of activity recognition and it is the toughest challenge in the field, and identification to the activities is the ultimate goal of such approaches. As with the passage of time there are huge amount of advancements in computing and sensor networks about which activity recognition techniques are totally dependent and precision cannot be met without these advancements in the certain fields. As sensor networks is becoming more and more advanced in this era, information is being collected from various ways, such as sensors are attached with body [9], or if not possible then stitched in the clothes [10], [11]. For the other movements like sitting, walking, climbing and falling, etc. [12], [13]; for the collection of data from gestures and postures [14]-[18]; and moving to some other activities like sleeping, eating and cooking, it acquires location based sensors which are used to determine activity in indoor environments [19], [20]. So, from the subject of smart city applications, we can also create intelligent application for environment such as smart environment which has been adopted widely for health monitoring [21] and with strong power source these can be affective for collection of data for a long time [22]. And to recognize these activities we are required with some models that can detect the class of an activity and understand the differences between the activities i.e. difference between walking and running, cooking and eating, etc. So, these kinds of models can be labeled as activity models.

2) Pattern Discovery and Anomaly Detection: After being messed with the activity detection and recognition, the next step is to find out some patterns related to a human on the basis of activities being performed. It is based on the activities which are used to recognize through supervised learning. Even unsupervised learning can get into it and a system can learn some activities by itself after observing recurrent sequences of some activity. There is a huge research work regarding the methods for the mining with respect to activities, its includes mining of some frequent sequences [23], and in [24] activities are mined in the form of patterns implying the technique of regular

expression

on it, and constraint or restriction based mining [25] and mining the patterns which occurs periodically and are frequent [26], [27]. And for the detection of interleaved patterns, [28] implemented a genetic algorithm in a different manner than the previous one i.e. by implying unsupervised learning in it. This discovering of patterns is of extreme wealth because once they are formed, then can be extremely useful in detecting the instance if the same pattern occurs again.

3) Planning and Scheduling: Planning and scheduling of any machine is very important. It can be very fruitful in much AmI application when we automate them. In automatic planning, we take an initial state or some initial background and on the basis of these initial knowledge it takes possible actions accordingly. It can be helpful in many AmI application and care related environment. For example, it can be useful in daily scheduling activities in an efficient manner so that many dementia and liver patient can be facilitated. In the past research work many planning techniques are proposed, from which a few are mentioned in Table 2.

4) Decision Support: Decision support systems (DSSs) [34]-[36] are mostly used in healthcare environments for assisting and analyzing the data of patients [37]-[42]. In DSSs we have mainly two main stream approaches, one is knowledge based and the other is non-knowledge based.

In knowledge based, we have vocabulary that is stored in database and the inference engine that contains the rules according to different set of information. It also comprised with IF-ELSE rules, where the engine combines the set of rules from the database in order to generate new knowledge and perform set of action accordingly. Different methods are proposed in past those are using this technique [43]. Whereas, in non-knowledge-based DSSs, no direct information or knowledge is provided, but it learns the rules from the past experience. Different algorithms and decision trees are also proposed for learning knowledge.

Both these techniques are frequently used in AmI for enhancing communication skills of doctors and nurses. DSS based Context-aware knowledge is also proposed that can gather data from their environment and take decisions accordingly [44].

5) Privacy Preserving Techniques: As AmI systems are getting fame, more information will be gathered through individuals. So, the information is very sensitive and critical. This creates many privacy issues from which many privacy concerns focus on sensitive monitoring [45]. Many AmI system are deployed with internet that can create lots of problems like internal or external attacks so many techniques are also proposed and these techniques are quite mature [46]. Also many approaches are developed to ensure that, critical and sensitive data cannot be gleaned from mined patterns. [47], [48]. 
TABLE II. METHODS USED IN AI FOR BIOMEDICAL DOMAIN

\begin{tabular}{|l|l|l|}
\hline Methods & Reference & Implemented Technique \\
\hline Decision-theoretic & {$[29]$} & Markov decision processes \\
\hline Search methods & {$[30]$} & Forward and Backward \\
\hline Graph-based & {$[31]$} & Graph plane \\
\hline Hierarchal & {$[32]$} & O-plan \\
\hline Hierarchal & {$[33]$} & Reactive plan \\
\hline
\end{tabular}

\section{APPLICATIONS AND EXPERT SYSTEMS OF ARTIFICIAL} INTELLIGENCE GETTING USED IN BIOMEDICAL FIELD

\section{A. Expert Systems of Biomedical and Healthcare}

a) Fuzzy Expert Systems in Medicine: Fuzzy logic is a technique which is used for data handling purpose that allows ambiguity, and particularly used in medical field. This expert system gets and uses the idea of fuzziness in a computationally efficient way. This technique is used in many medical fields such as multiple logistic regression analysis and also used for the diagnosis of many diseases like lungs cancer, acute leukaemia, breast and pancreatic cancer. Fuzzy expert system can also predict about the survival of patient who is suffering from breast cancer [49].

b) Automated Fraud Detection in Health care sector: It is a new medical technology of AI where, the system monitors the employer having sick leave by monitoring its activities on social media. This application presumably analyzes sick employees when they post their status on social media, then investigates that either they are sick or not, but skipping their time and work [50]. The tools of data analytics in this system works automatically and thus, these systems intelligently learn automatically by their own [51].

c) Medical adherence application for mobile devices (AiCure): This application of AI facilitates the patient about the information of disease and its treatment, conforming ingestion and reminds patient for medication doses according to the time table of patient [50]. When patient perform incorrect behavior then system identifies, acknowledges this behavior to doctor and provides data to the doctor for the remedy [52].

d) Care-O-bot 3 (Fraunhofer IPA): In this system, a robot helps and aids a patient in his house. By designing a map, the robot navigates automatically to approach a target by adjusting itself on the map and avoiding the obstacles. The robot can also provide the facilitation to bring and fetch service by learning the object [53] and it works according to the order of user by technique of face recognition.

e) Evolutionary Computation in Medicine: Evolutionary computation is a general expression for various computational methods which is based on the process of natural evolution that mimics the procedure of natural selection. Genetic algorithm is the most useful form of evolutionary computation in medical areas [54]. The rule of genetic algorithm is majorly used to predict the outcome of seriously ill patient. In MRI segmentation of brain tumors, evaluating the adequacy of treatment strategy and it is handled by evolutionary computations [55]. Computerized analysis of mammographic micro categorization is also done by evolutionary computation.

f) Artificial Intelligence to Improve Hospital Inpatient Care: Clinical decision support system is one of the most popular methods of AI. This expert system is initially focusing in diagnosing the condition of patient by giving demographic information and his symptoms. Mycin is another expert system developed in 1970 based on rules used for the diagnosis and identification of bacteria and then recommends antibiotics for the treatment of infected patient [56]. Pathfinder is another method used for the identification of lymph-node disease for the support of pathologist. This method used Bayesian network and such technique helps for the diagnosis of varying form of cancer and for unexpected heart diseases [57].

g) Artificial Intelligence Approaches for Medical Image Classification: Some applications of AI are used for diagnostic sciences in categorization of different type of biomedical image such as identify tumors in brain etc. Decision-support tools and model-based intelligent system are very useful methods for the medical image classification for analysis and evaluation purpose. CAD support radiologist that uses the result taken from the computerized analysis of those tools [58]. These tools help radiologist to increase the accuracy of results taken from such expert systems and to minimize the rate of errors [59].

h) Implementation Scheme for Online Medical Diagnosis System Using Multi Agent System with JADE: In this paper the idea of online medical service is formulated for the users of internet. The working of this multi-agent based system is well but has some challenges:

i) Communication of Services.

ii) Data Security.

iii) Interconnection of User and Agent.

iv) Synchronization of Different Services.

The main purpose of this system is to build a type of system that could have the ability to run in all environments. The Agent Communication Channel (ACC) is another module which connects the remote and local platforms [60]. This framework is created by JADE and whenever JADE launches, the ACC starts its communication.

\section{B. Usage of Artificial Neural Network based Techniques in Biomedical Domain}

a) MRI Brain Tumor Analysis: Some ANN techniques used for the classification of images in diagnostic science. A general regression neural network (GRNN) is used as a three dimensional technique of classification for the image of brain tumor [61]. Least Squares Support Vector Machines (LSSVM) is another proposed method used for the diagnosis of normal and abnormal areas of brain from data of MRI [62]. 
Because of autonomous way to classify MRI image, it shows result with greater accuracy than other classifiers.

b) Endoscopic Images: Advanced fuzzy inference neural network is a technique for classification of endoscopic images. This technique works by merging the methods of fuzzy systems and radial based function. By this idea of mixture of many classifiers it shows particular parameters and features with an accuracy of $94.28 \%$. However, radial based function classifies the fast rate of training than fuzzy systems [63]. These types of techniques show their results by both statistical and texture features [64].

c) Heart Disease Classification: Artificial neural network has also proved its ability by working on the classification of heart disease. In this technique for the classification of stroke, the input of sensor is given to the system that uses [65] forward feed network with the rule of back propagation way [66]. Effective result of classification is given by simulation system which is then moved forward to the network for testing purpose.

d) Decision Support System to Diagnose Nodules: Through the concept of ANN, a new system is proposed and known as decision support system (DSS). A decision support system that diagnoses nodules into benign, malignant and identify [67] its severity by the analysis the collected data. This known method has delivered the accuracy up to $95 \%$ by collecting the dataset of 63 samples [68].

\section{RESUlTS AND DisCUSSIONS}

So far in the literature review, it is witnessed that the Artificial Intelligence with the concepts or domains of, Machine Learning, Natural Language Processing, Neural Networks and advanced computing, health care facilities are made fast and quick. Not only this, healthcare process is automated as good as it can detect some anomaly from the activities presuming that something severe is going to happen. Through this, it can put alarms on and emergency alert at house level. We can say that after the smart city concept in terms of computing and Internet of Things (IoT), the new concept is smart house or smart environment with respect to healthcare, and from this concept each and every personnel can get benefits.

Table 3 shows some examples of expert systems and their description about the purpose for which they are implemented. We have evaluated the improvement of the systems in medical and clinical with stars. The highest possibility of rank for a system is 5 stars and 5 stars are awarded to those systems which have ideal accuracy i.e. above 99\%. There is also a discussion about the type of systems, that what kind of logic they are using. It is of high worth to mention about the expert systems and fuzzy expert system to demonstrate the types of the systems as mentioned in Table 3.

TABLE III. GRADING OF EXPERT SYSTEMS IN CLINICAL

\begin{tabular}{|c|c|c|c|c|c|}
\hline System & Ref \# & Purpose & Type & Performance & $\begin{array}{l}\text { Improvement } \\
\text { (GRADING) }\end{array}$ \\
\hline 1 & [69] & $\begin{array}{l}\text { Improving quality of first } \\
\text { aids }\end{array}$ & Expert system & Improved & \\
\hline 2 & [70] & Prediction of low back pain & $\begin{array}{l}\text { ANN and adaptive neuro-fuzzy } \\
\text { inference system }\end{array}$ & $\begin{array}{l}\text { Few systems detected pain } \\
\text { successfully }\end{array}$ & \\
\hline 3 & [71] & $\begin{array}{l}\text { Identifying the type of } \\
\text { neuropathy }\end{array}$ & Fuzzy expert system & $93.26 \%$ & \\
\hline 4 & [72] & $\begin{array}{l}\text { Diagnosing types of } \\
\text { headache }\end{array}$ & Expert system & $98 \%$ & \\
\hline 5 & [73] & Diagnosis of tuberculosis & $\begin{array}{l}\text { ANN optimized with genetic } \\
\text { algorithm }\end{array}$ & $94.88 \%$ & \\
\hline 6 & [74] & Diagnosing strabismus & $\begin{array}{l}\text { Web-based neural network } \\
\text { system }\end{array}$ & $100 \%$ & \\
\hline 7 & $\begin{array}{l}{[75],} \\
{[76]}\end{array}$ & $\begin{array}{l}\text { Diagnosis of hepatitis and } \\
\text { its fatality }\end{array}$ & $\begin{array}{l}\text { Multilayer neural network based } \\
\text { on Levenberg-Marquardt (LM) } \\
\text { algorithm and a probabilistic } \\
\text { neural network (PNN) }\end{array}$ & $\begin{array}{l}91.2 \% \\
91.87 \%\end{array}$ & 负 \\
\hline 8 & [77] & $\begin{array}{l}\text { Suggesting radiotherapy } \\
\text { regimen based on anatomy }\end{array}$ & $\begin{array}{l}\text { A combination of an expert } \\
\text { system and ANN }\end{array}$ & $96 \%$ & $\grave{n}$ \\
\hline
\end{tabular}




\begin{tabular}{|c|c|c|c|c|c|}
\hline 9 & [78] & $\begin{array}{l}\text { Analyzing serology } \\
\text { laboratory tests and } \\
\text { providing expert advice } \\
\text { and possible disease }\end{array}$ & Web-based fuzzy expert system & $91 \%$ & $\widehat{h}$ \\
\hline 10 & [79] & $\begin{array}{l}\text { Prescribing the most } \\
\text { appropriate Chinese } \\
\text { acupuncture treatment }\end{array}$ & Expert system & -- & 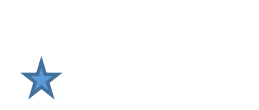 \\
\hline 11 & [80] & Diagnosis of breast cancer & $\begin{array}{l}\text { Support vector machine (SVM), } \\
\text { Naïve Bayes classifier (NBC) and } \\
\text { ANN based on color wavelet } \\
\text { features }\end{array}$ & $98.3 \%$ & 支 \\
\hline 12 & [81] & Classification of heartbeats & $\begin{array}{l}\text { Wavelet neural network (WNN) } \\
\text { based on features extracted from } \\
\text { ECG }\end{array}$ & $98.78 \%$ & $\checkmark$ 卉 \\
\hline 13 & [82] & Differentiating heartbeats & Fuzzy expert system & $90-95 \%$ & 市负 \\
\hline 14 & [83] & $\begin{array}{l}\text { Identifying diabetic } \\
\text { retinopathy }\end{array}$ & Different ANN classifiers & $94 \%$ & 苁 \\
\hline
\end{tabular}

An expert system is a computational based system which emulates the reasoning process of a human expert e.g. it is evolved in such a way that it has the capability to think like intelligent human mind, reasoning like an expert human being and to take decisions like a professional mind. In fact, expert systems are the mimicry of human mind that is expert to some particular field. These expert systems are applied throughout the world for different purposes but some of well demonstrated purposes include consulting, diagnostic, learning, designing, planning and decision support. Whereas, the working of fuzzy expert system involves fuzzy set theory instead of linear algebra or Boolean function, and the knowledge is normally presented in the form of some fuzzy production rules i.e. the most common example is 'IF $\mathrm{X}$ THEN Y', where $\mathrm{X}$ and $\mathrm{Y}$ are fuzzy sets. And these fuzzy sets are said to be 'rulebase' or knowledge base of a fuzzy expert system.

\section{CONCLUSION AND FUTURE DiRECTIONS}

In this paper, we critically explored the branches of artificial intelligence within the biomedical and healthcare sectors. The information is presented in a very concise way and investigated the performance of some expert systems that are employed in the healthcare domain. We hope, this research work will be helpful for the new researchers of AI to explore this particular domain in an appropriate way and make the field of AI more robust and applicable is sense of performance in the healthcare. Medicine has shaped as an upscale testbed for ML experimental findings within the previous decade, permitting researches and developers to evolve advanced and complicated systems with super power of learning ability. Whereas, we witness abundant sensible use of knowledgeable tools in the clinical recommendations. Now a days, ML based systems appear to be utilized with lot of experimental manner. Therefore, there are many aspects and conditions in medical where these approaches can be used and can perform a huge contribution the field healthcare.

To make this AI even more powerful, organizations have to implement better hardware architectures like pervasive or ubiquitous hardware approaches. These systems will be able to search for the data that is not in the same place [4]. This will improve data mining techniques and we will be able to search for a solution on a bigger scale. The future of AI is not just limited to this, it will recognize people's expressions, mood, need and will respond to these emotions as they would be preprogrammed to do [59]. As the world is becoming a global village, we are facing the privacy issues more and more. As we add more devices to the system that means we are increasing the privacy issues more and more wide and easy [84]. Ambient Intelligence (Aml) can increase the number of security concerns because it accesses many other devices which increases the breach points. Aml sensors will use wireless protocols that could be intercepted easily. To avoid this situation, every communication should be encrypted, biometric authentication should be used to verify the concerned person [85]. Privacy by Design $(\mathrm{PbD})$ should be taken into account because, it sets privacy on the sensor devices once and privacy limits got set for future as well.

\section{REFERENCES}

[1] "One hundred year study on Artificial Intelligence (AI100)", Stanford University, https://ai100.stanford.edu.

[2] Forestier, Germain, et al. "Automatic matching of surgeries to predict surgeons' next actions." Artificial Intelligence in Medicine (2017).

[3] Jha, Saurabh, and Eric J. Topol. "Adapting to artificial intelligence: radiologists and pathologists as information specialists." JAMA 316.22 (2016): 2353-2354.

[4] Hamet, Pavel, and Johanne Tremblay. "Artificial Intelligence in Medicine." Metabolism (2017). 
[5] Hansen, Karl R., et al. "Predictors of pregnancy and live-birth in couples with unexplained infertility after ovarian stimulation-intrauterine insemination." Fertility and sterility 105.6 (2016): 1575-1583.

[6] G. Singla, D. Cook, and M. Schmitter-Edgecombe, "Recognizing independent and joint activities among multiple residents in smart environments,'” J. Ambient Intell. Humanized Comput., vol. 1, no. 1, pp. $57-63,2010$.

[7] L. Chen, J. Hoey, C. Nugent, D. Cook, and Z. Hu, "Sensor-based activity recognition," IEEE Trans. Syst. Man Cybern. C, Appl. Rev., vol. 42, no. 6, pp. 790-808, Nov. 2012.

[8] P. Rashidi, D. Cook, L. Holder, and M. Schmitter-Edgecombe, "Discovering activities to recognize and track in a smart environment," IEEE Trans. Knowl. Data Eng., vol. 23, no. 4, pp. 527-539, Apr. 2011.

[9] A. Yang, R. Jafari, S. Sastry, and R. Bajcsy, "Distributed recognition of human actions using wearable motion sensor networks," J. Ambient Intell. Smart Environ., vol. 1, no. 2, pp. 103-115, 2009.

[10] H. Harms, O. Amft, G. Tro"ster, and D. Roggen, "Smash: A distributed sensing and processing garment for the classification of upper body postures," in Proc. ICST 3rd Int. Conf. Body Area Netw., 2008, p. 22.

[11] C. Metcalf, S. Collie, A. Cranny, G. Hallett, C. James, J. Adams, P. Chappell, N. White, and J. Burridge, "Fabric-based strain sensors for measuring movement in wearable telemonitoring applications," in Proc. IET Conf. Assisted Living, 2009, pp. 1-4.

[12] U. Maurer, A. Smailagic, D. Siewiorek, and M. Deisher, "Activity recognition and monitoring using multiple sensors on different body positions," in Proc. Int. IEEE Workshop Wearable Implantable Body Sensor Netw., 2006, DOI: 10.1109/BSN.2006.6.

[13] R. Srinivasan, C. Chen, and D. Cook, "Activity recognition using actigraph sensor," in Proc. 4th Int. Workshop Knowl. Disc. Sensor Data, Washington, DC, USA, 2010, pp. 25-28.

[14] S. Lee and K. Mase, "Activity and location recognition using wearable sensors,'” IEEE Perv. Comput., vol. 1, no. 3, pp. 24-32, Jul.-Sep. 2002.

[15] R. Agrawal and R. Srikant, "Mining sequential patterns," in Proc. 11th Int. IEEE Conf. Data Eng., 1995, pp. 3-14.

[16] H. Junker, O. Amft, P. Lukowicz, and G. Tro"ster, "Gesture spotting with body-worn inertial sensors to detect user activities," Pattern Recognit., vol. 41, no. 6, pp. 2010-2024, 2008.

[17] N. Krishnan, P. Lade, and S. Panchanathan, "Activity gesture spotting using a threshold model based on adaptive boosting," in Proc. IEEE Int. Conf. Multimedia Expo, 2010, pp. 155-160.

[18] J. Mantyjarvi, J. Himberg, and T. Seppanen, "Recognizing human motion with multiple acceleration sensors," in Proc. IEEE Int. Conf. Syst. Man Cybern., 2001, vol. 2, pp. 747-752.

[19] D. Cook, "Learning setting-generalized activity models for smart spaces," IEEE Intell. Syst., vol. 27, no. 1, pp. 32-38, Jan.-Feb. 2012.

[20] C. Nugent, M. Mulvenna, X. Hong, and S. Devlin, "Experiences in the development of a smart lab," Int. J. Biomed. Eng. Technol., vol. 2, no. 4, pp. 319-331, 2009.

[21] T. van Kasteren, G. Englebienne, and B. Kro"se, "An activity monitoring system for elderly care using generative and discriminative models," Pers. Ubiquitous Comput., vol. 14, no. 6, pp. 489-498, 2010.

[22] B. Logan, J. Healey, M. Philipose, E. Tapia, and S. Intille, "A long-term evaluation of sensing modalities for activity recognition," in Proc. 9th Int. Conf. Ubiquitous Comput., 2007, pp. 483-500.

[23] T. Gao, T. Massey, L. Selavo, D. Crawford, B. rong Chen, K. Lorincz, V. Shnayder, L. Hauenstein, F. Dabiri, J. Jeng, A. Chanmugam, D. White, M. Sarrafzadeh, and M. Welsh, "The advanced health and disaster aid network: A light-weight wireless medical system for triage," IEEE Trans. Biomed. Circuits Syst., vol. 1, no. 3, pp. 203-216, Sep. 2007.

[24] T. Barger, D. Brown, and M. Alwan, "Health-status monitoring through analysis of behavioral patterns," IEEE Trans. Syst. Man Cybern. A, Syst. Humans, vol. 35, no. 1, pp. 22-27, Jan. 2005.

[25] J. Pei, J. Han, and W. Wang, "Constraint-based sequential pattern mining: The pattern-growth methods,' J. Intell. Inf. Syst., vol. 28, no. 2, pp. 133-160, 2007.
[26] P. Rashidi and D. J. Cook, "Keeping the resident in the loop: Adapting the smart home to the user," IEEE Trans. Syst. Man Cybern. A, Syst. Humans, vol. 39, no. 5, pp. 949-959, Sep. 2009.

[27] E. Heierman, III, and D. Cook, "Improving home automation by discovering regularly occurring device usage patterns," in Proc. 3rd IEEE Int. Conf. Data Mining, 2003, pp. 537-540.

[28] M. Ruotsalainen, T. Ala-Kleemola, and A. Visa, "Gais: A method for detecting interleaved sequential patterns from imperfect data," in Proc. IEEE Symp. Comput. Intell. Data Mining, 2007, pp. 530-534.

[29] Abel, David, James MacGlashan, and Michael L. Littman. "Reinforcement Learning As a Framework for Ethical Decision Making." Workshops at the Thirtieth AAAI Conference on Artificial Intelligence. 2016.

[30] Cserna, Bence, et al. "Anytime versus Real-Time Heuristic Search for On-Line Planning." Ninth Annual Symposium on Combinatorial Search. 2016.

[31] Zhou, Xiaolu, Mingshu Wang, and Dongying Li. "From stay to play-A travel planning tool based on crowdsourcing user-generated contents." Applied Geography 78 (2017): 1-11.

[32] Wickler, Gerhard, Lukás Chrpa, and Thomas Leo McCluskey. "KEWIA Knowledge Engineering Tool for Modelling AI Planning Tasks." KEOD. 2014.

[33] Michaud, François, and Monica Nicolescu. "Behavior-based systems." Springer Handbook of Robotics. Springer International Publishing, 2016. 307-328.

[34] Bonczek, Robert H., Clyde W. Holsapple, and Andrew B. Whinston. Foundations of decision support systems. Academic Press, 2014.

[35] S. Eom and E. Kim, "A survey of decision support system applications (1995-2001),”' J. Oper. Res. Soc., vol. 57, no. 11, pp. 1264-1278, 2006.

[36] Mitchell, Jordan, et al. "Informatics for Health and Social Care Differences in pneumonia treatment between high-minority and lowminority neighborhoods with clinical decision support system implementation between high-minority and low-minority neighborhoods with clinical decision." (2016).

[37] Massam, Bryan H., and Jacek Malczewski. "The location of health centers in a rural region using a decision support system: a Zambian case study." Geography Research Forum. Vol. 11. 2016.

[38] Weaver, Charlotte A., et al. "Healthcare information management systems." Cham: Springer International Publishing (2016).

[39] Mitchell, Jordan, et al. "Differences in pneumonia treatment between high-minority and low-minority neighborhoods with clinical decision support system implementation." Informatics for Health and Social Care 41.2 (2016): 128-142.

[40] Gray, Carolyn Steele, et al. "Supporting goal-oriented primary health care for seniors with complex care needs using mobile technology: evaluation and implementation of the health system performance research network, Bridgepoint electronic patient reported outcome tool." JMIR Research Protocols 5.2 (2016).

[41] M. Romano and R. Stafford, "Electronic health records and clinical decision support systems: Impact on national ambulatory care quality," Arch. Internal Med., vol. 171, no. 10, pp. 897-903, 2011.

[42] M. Perwez, N. Ahmad, M. Javaid, and M. Ehsan Ul Haq, "A critical analysis on efficacy of clinical decision support systems in health care domain,” Adv. Mater. Res., vol. 383-390, pp. 4043-4050, 2012.

[43] M. Kaptein, P. Markopoulos, B. de Ruyter, and E. Aarts, "Persuasion in ambient intelligence," J. Ambient Intell. Humanized Comput., vol. 1, no. 1 , pp. 43-56, 2010.

[44] Furmankiewicz, M., A. Sołtysik-Piorunkiewicz, and P. Ziuziański. "Artificial intelligence systems for knowledge management in e-health: the study of intelligent software agents." Latest Trends on Systems: The Proceedings of 18th International Conference on Systems, Santorini Island, Greece. 2014

[45] G. Demiris, D. Oliver, G. Dickey, M. Skubic, and M. Rantz, "Findings from a participatory evaluation of a smart home application for older adults," Technol. Health.

[46] Huang, Tien-Chi, Chia-Chen Chen, and Yu-Wen Chou. "Animating ecoeducation: To see, feel, and discover in an augmented reality-based 
experiential learning environment." Computers \& Education 96 (2016): 72-82.

[47] Panagiotakis, Costas, and Georgios Tziritas. "A minimum spanning tree equipartition algorithm for micro aggregation." Journal of Applied Statistics 42.4 (2015): 846-865.

[48] 7hano Rvouno-tak "Artificial intellioence and medicine." 춘- 추계 학술대회 (KASL) 2016.2 (2016): 65-65.

[49] Arsene, Octavian, Ioan Dumitrache, and Ioana Mihu. "Expert system for medicine diagnosis using software agents." Expert Systems with Applications 42.4 (2015): 1825-1834.

[50] Hengstler, Monika, Ellen Enkel, and Selina Duelli. "Applied artificial intelligence and trust-The case of autonomous vehicles and medical assistance devices." Technological Forecasting and Social Change 105 (2016): 105-120.

[51] West, Jarrod, and Maumita Bhattacharya. "Intelligent financial fraud detection: a comprehensive review." Computers \& Security 57 (2016): 47-66.

[52] Gravenhorst, Franz, et al. "Mobile phones as medical devices in mental disorder treatment: an overview." Personal and Ubiquitous Computing 19.2 (2015): 335-353.

[53] Šabanović, Selma, et al. "A robot of my own: participatory design of socially assistive robots for independently living older adults diagnosed with depression." International Conference on Human Aspects of IT for the Aged Population. Springer International Publishing, 2015.

[54] Inbarani, H. Hannah, Ahmad Taher Azar, and G. Jothi. "Supervised hybrid feature selection based on PSO and rough sets for medical diagnosis." Computer methods and programs in biomedicine 113.1 (2014): 175-185.

[55] Eiben, Agoston E., and Jim Smith. "From evolutionary computation to the evolution of things." Nature 521.7553 (2015): 476-482.

[56] Neill, Daniel B. "Using artificial intelligence to improve hospital inpatient care." IEEE Intelligent Systems 28.2 (2013): 92-95.

[57] Musen, Mark A., Blackford Middleton, and Robert A. Greenes. "Clinical decision-support systems." Biomedical informatics. Springer London, 2014. 643-674.

[58] Berner, Eta S., and Tonya J. La Lande. "Overview of clinical decision support systems." Clinical decision support systems. Springer International Publishing, 2016. 1-17.

[59] S.N. Deepa, B. Aruna Devi, "A survey on artificial intelligence approaches for medical image classification", Indian Journal of Science and Technology, Vol. 4 No. 11 (Nov 2011).

[60] Gupta, S., Sarkar, A., Pramanik, I. and Mukherjee, B. Implementation Scheme for Online Medical Diagnosis System Using Multi Agent System with JADE. International Journal of Scientific and Research Publications, Volume 2, Issue 6, June 2012.

[61] Londhe, Vaishali. "Brain MR Image Segmentation for Tumor Detection using Artificial Neural.” Brain 6.1 (2017).

[62] Pannu, Avneet. "Artificial intelligence and its application in different areas.” Artificial Intelligence 4.10 (2015).

[63] Vassilis S Kodogiannis and John N Lygouras (2008) Neuro-fuzzy classification system for wireless capsule endoscopic images. J. World Acad. Sci.Engg. \& Technol., 45, 620-628.

[64] Roberts, Kirk, et al. "State-of-the-art in biomedical literature retrieval for clinical cases: a survey of the TREC 2014 CDS track." Information Retrieval Journal 19.1-2 (2016): 113-148.

[65] Masethe, Hlaudi Daniel, and Mosima Anna Masethe. "Prediction of heart disease using classification algorithms." Proceedings of the world congress on engineering and computer science. Vol. 2. 2014.

[66] Patel, Ankeeta R., and Mandar M. Joshi. "Heart diseases diagnosis using neural network." In Computing, Communications and Networking Technologies (ICCCNT), 2013 Fourth International Conference on, pp. 1-5. IEEE, 2013.
[67] Maltas, Ahmet, Ali Alkan, and Mustafa Karabulut. "Use of artificial neural network algorithm in the immunohistochemical dyeing based diagnosis of thyroid tumor." In Signal Processing and Communications Applications Conference (SIU), 2014 22nd, pp. 1106-1109. IEEE, 2014.

[68] Filimon, Delia-Maria, and Adriana Albu. "Skin diseases diagnosis using artificial neural networks." In 2014 IEEE 9th IEEE International Symposium on Applied Computational Intelligence and Informatics (SACI). 2014.

[69] Ertl, L., and Christ, F., Significant improvement of the quality of bystander first aid using an expert system with a mobile multimedia device. Resuscitation 74:286-295, 2007.

[70] M., Gulbandilar, E., and Cimbiz, A., Prediction of low back pain with two expert systems. J. Med. Syst. 36:1523-1527, 2012.

[71] Kunhimangalam, R., Ovallath, S., and Joseph, P. K., A clinical decision support system with an integrated EMR for diagnosis of peripheral neuropathy. J. Med. Syst. 38:38, 2014.

[72] Maizels, M., and Wolfe, W., An expert system for headache diagnosis: The computerized headache assessment tool (CHAT). Headache 48:7278, 2008.

[73] Elveren, E., and Yumusak, N., Tuberculosis disease diagnosis using artificial neural network trained with genetic algorithm. J. Med. Syst. 35:329-332, 2011.

[74] Fisher, A. C., Chandna, A., and Cunningham, I. P., The differential diagnosis of vertical strabismus from prism cover test data using an artificially intelligent expert system. Med. Biol. Eng. Comput. 45: 689693, 2007.

[75] Bascil, M. S., and Temurtas, F., A study on hepatitis disease diagnosis using multilayer neural network with Levenberg Marquardt training algorithm. J. Med. Syst. 35:433-436, 2011.

[76] Bascil, M. S., and Oztekin, H., A study on hepatitis disease diagnosis using probabilistic neural network. J. Med. Syst. 36:1603-1606, 2012.

[77] Wells, D. M., and Niedere, J., A medical expert system approach using artificial neural networks for standardized treatment planning. Int. J. Radiat. Oncol. Biol. Phys. 41:173-182, 1998.

[78] Basciftci, F., and Incekara, H., Design of web-based fuzzy input expert system for the analysis of serology laboratory tests. J. Med. Syst. 36:2187-2191, 2012.

[79] Lam, C. F. D., Leung, K. S., Heng, P. A., Lim, C. E. D., and Wong, F. W. S., Chinese acupuncture expert system (CAES): A useful tool to practice and learn medical acupuncture. J. Med. Syst. 36:1883-1890, 2012.

[80] Issac Niwas, S., Palanisamy, P., Chibbar, R., and Zhang, W. J., An expert support system for breast cancer diagnosis using color wavelet features. J. Med. Syst. 36:3091-3102, 2012.

[81] Benali, R., Reguig, F. B., and Slimane, Z. H., Automatic classification of heartbeats using wavelet neural network. J. Med. Syst. 36: 883-892, 2012.

[82] Exarchos, T. P., Tsipouras, M. G., Exarchos, C. P., Papaloukas, C., Fotiadis, D., and Michalis, L. K., A methodology for the automated creation of fuzzy expert systems for ischaemic and arrhythmic beat classification based on a set of rules obtained by a decision tree. Artif. Intell. Med. 40:187-200, 2007.

[83] Kumar, S. J. J., and Madheswaran, M., An improved medical decision support system to identify the diabetic retinopathy using fundus images. J. Med. Syst. 36:3573-3581, 2012.

[84] Ondiege, Brian, and Malcolm Clarke. "Healthcare professionals' perception of security of Personal Health Devices." (2017).

[85] Khan, Iqbal Uddin, and Sadiq ur Rehman. "A Review on Big Data Security and Privacy in Healthcare Applications." Big Data Management. Springer International Publishing, 2017. 71-89. 